\title{
Correction to: Biologic monotherapy in the biologic naïve patient with rheumatoid arthritis (RA): results from an observational study
}

\author{
Rosalind Benson $^{1} \cdot$ Sizheng Steven Zhao ${ }^{2}\left[\right.$ - Nicola Goodson ${ }^{2}\left(\mathbb{D} \cdot\right.$ Rikki Abernethy $^{3} \cdot$ Devesh Mewar $^{1}$. \\ Theresa Barnes ${ }^{4}$
}

Published online: 2 April 2020

(c) Springer-Verlag GmbH Germany, part of Springer Nature 2020

\section{Correction to: Rheumatology International https://doi.org/10.1007/s00296-020-04531-6}

In the original article, the corresponding author's given name and middle name were interchanged as given by the authors in the original manuscript. The correct name is Sizheng Steven Zhao.

The original article has been corrected.

Publisher's Note Springer Nature remains neutral with regard to jurisdictional claims in published maps and institutional affiliations.

The original article can be found online at https://doi.org/10.1007/ s00296-020-04531-6.

Sizheng Steven Zhao

theresa.barnes@nhs.net; s.zhao8@liv.ac.uk

1 Liverpool University Hospitals NHS Foundation Trust, Royal Liverpool University Hospital, Prescot Street, Liverpool L7 8XP, UK

2 Liverpool University Hospitals NHS Foundation Trust, Aintree University Hospital, Lower Lane, Liverpool L9 7AL, UK

3 St Helens and Knowsley Teaching Hospitals NHS Trust, Warrington Rd, Prescot L35 5DR, UK

4 Department of Rheumatology, Countess of Chester Hospital, Liverpool Rd, Chester CH2 1UL, UK 